\title{
The Center of Lifespan Psychology at the Max Planck Institute for Human Development: Conceptual Agenda and Illustration of Research Activities
}

\author{
Shu-Chen Li, Martin Lövdén, Sabine Schaefer, Florian Schmiedek, Yee Lee Shing, Markus \\ Werkle-Bergner, and Ulman Lindenberger
}

(Center for Lifespan Psychology, Max Planck Institute for Human Development, Berlin, Germany)

\begin{abstract}
Founded in 1981 by the late Paul B. Baltes, the Center for Lifespan Psychology at the Max Planck Institute for Human Development has helped to establish lifespan psychology as a distinct conceptual approach within developmental psychology. Since 2004, the Center has extended its research program into developmental behavioral neuroscience. Work at the Center is guided by three propositions: (i) to study lifespan changes in behavior as interactions among maturation, learning, and senescence; (ii) to develop theories and methods that integrate empirical evidence across domains of functioning, timescales, as well as behavioral and neuronal levels of analysis; (iii) to identify mechanisms of development by exploring age-graded differences in plasticity. The Center continues to pay special attention to the age periods of late adulthood and old age, which offer unique opportunities for innovation, both in theory and practice. At the same time, it has intensified its interest in early periods of ontogeny including infancy and early childhood. In this article we report recent findings from four research projects focusing on sensory and cognitive development at behavioral and neural levels of analysis.

Key words: The Center of Lifespan Psychology at the Max Planck Institute for Human Development; conceptual agenda; research activities; late adulthood and old age
\end{abstract}

Since its foundation in 1981 under the leadership of the late Paul B. Baltes, the Center for Lifespan Psychology at the Max Planck Institute for Human Development has promoted a perspective on behavioral development that seeks

Received date: 2009-03-23

This article is an updated version of an earlier publication (Lindenberger, Li, Lövdén, \& Schmiedek, 2007). The authors would like to thank all their current and past colleagues from the Center for Lifespan Psychology for their contributions to the scientific work reported in this article. Particularly, we express our gratitude to the founding director of the Center for Lifespan Psychology, Paul B. Baltes (1939-2006), who shaped the scientific profile of the Center for more than two decades and laid the foundation for its current research agenda.

Address correspondence regarding this article to Ulman Lindenberger (E-mail: seklindenberger@mpibberlin.mpg.de) or Shu-Chen Li (E-mail: shuchen@, mpib-berlin.mpg.de), Lentzeallee 94, 14195 Berlin, Germany. to integrate age periods, domains of functioning, timescales, and levels of analysis. In part through these efforts, lifespan psychology has evolved into a distinct conceptual approach within developmental psychology (e.g., Baltes, 1987; Baltes, Lindenberger, \& Staudinger, 1998, 2006). More recently, the Center for Lifespan Psychology has extended the conceptual and the empirical scope of its scientific endeavors into the field of developmental behavioral neuroscience (Lindenberger, Li, \& Bäckman, 2006; cf. Craik, 2006; Craik \& Bialystok, 2006). We begin this article with an outline of the three interrelated propositions that build the foundation of the Center's research agenda. Then, four of the eight research projects currently conducted at the Center will be presented in more detail. Table 1 provides an overview of the Center's current research projects and their scientific investigators. 
Table 1

The Center for Lifespan Psychology at the Max Planck Institute for Human Development: Overview of Research Projects

\begin{tabular}{|c|c|c|}
\hline Name of Project & $\begin{array}{c}\text { Research scientists and postdoctoral research } \\
\text { fellows }\end{array}$ & Select Recent Publications \\
\hline $\begin{array}{l}\text { Neuromodulation of lifespan } \\
\text { cognition }\end{array}$ & $\begin{array}{l}\text { Shu-Chen Li**; Lars Bäckman, Hauke } \\
\text { Heekeren, Ulman Lindenberger }\end{array}$ & $\begin{array}{l}\text { Li, Hämmerer, Müller, Hommel, } \\
\text { \& Lindenberger (in press) } \\
\text { Lindenberger, Nagel, Chicherio, } \\
\text { Li, Heekeren, \& Bäckman } \\
\text { (2008) }\end{array}$ \\
\hline $\begin{array}{l}\text { Intra-Person dynamics across the } \\
\text { lifespan }\end{array}$ & $\begin{array}{l}\text { Florian Schmiedek**, Martin Lövdén**; } \\
\text { Yee Lee Shing, Manuel Völkle, Markus } \\
\text { Werkle-Bergner, Ulman Lindenberger }\end{array}$ & $\begin{array}{l}\text { Schmiedek, Hildebrandt, } \\
\text { Lövdén, Wilhelm, \& } \\
\text { Lindenberger (in press) } \\
\text { Lövdén, Li, Shing, \& } \\
\text { Lindenberger (2007) }\end{array}$ \\
\hline $\begin{array}{l}\text { CONMEM: Cognitive and } \\
\text { neuronal } \\
\text { dynamics of memory across the } \\
\text { lifespan }\end{array}$ & $\begin{array}{l}\text { Yee Lee Shing**, Markus Werkle-Bergner**; Rc } \\
\text { Freunberger*, Ulman Lindenberger }\end{array}$ & $\begin{array}{l}\text { Shing, Werkle-Bergner, Li, } \\
\text { Lindenberger (2008) } \\
\text { Werkle-Bergner, Müller, Li, } \\
\text { Lindenberger (2006) }\end{array}$ \\
\hline Sensorimotor-cognitive couplings & Sabine Schaefer**; Ulman Lindenberger & $\begin{array}{l}\text { Schaefer, Krampe, Lindenberger, } \\
\text { \& Baltes (2008) } \\
\text { Verrel, Lövdén, Schellenbach, } \\
\text { Schaefer, \& Lindenberger (in } \\
\text { press) }\end{array}$ \\
\hline BASE: The Berlin Aging Studies & $\begin{array}{l}\text { Ulman Lindenberger**; Julia Delius, Hauke } \\
\text { Heekeren, Shu-Chen Li, Florian Schmiedek }\end{array}$ & $\begin{array}{l}\text { Lindenberger \& Ghisletta (2009) } \\
\text { Gerstorf, Ram, Röcke, } \\
\quad \text { Lindenberger, \& Smith (2008) }\end{array}$ \\
\hline $\begin{array}{l}\text { DRAMA: Developmental } \\
\text { regulation of affect, motivation, } \\
\text { and abilities }\end{array}$ & $\begin{array}{l}\text { Michaela Riediger**; Sabine Schaefer, Antje } \\
\text { Rauers*, Ulman Lindenberger }\end{array}$ & $\begin{array}{l}\text { Riediger \& Freund (2008) } \\
\text { Ebner, Riediger, \& Lindenberger } \\
\quad \text { (in press) }\end{array}$ \\
\hline $\begin{array}{l}\text { Interactive brains, social brain } \\
\text { minds }\end{array}$ & $\begin{array}{l}\text { Ulman Lindenberger**; Anna Keinspehn* } \\
\text { Franziska Kopp, Shu-Chen Li, Viktor Müller }\end{array}$ & $\begin{array}{l}\text { Lindenberger, Li, Gruber, \& } \\
\text { Müller (in press) } \\
\text { Müller, Gruber, Klimesch, \& } \\
\text { Lindenberger (in press) }\end{array}$ \\
\hline $\begin{array}{l}\text { Formal methods in lifespan } \\
\text { psychology }\end{array}$ & Timo von Oertzen**; Ulman Lindenberger & $\begin{array}{l}\text { von Oertzen, T. (in press) } \\
\text { Hertzog, von Oertzen, } \\
\text { Lindenberger, \& Ghisletta } \\
(2008)\end{array}$ \\
\hline
\end{tabular}

Note. The table refers to projects and project members as of February, 2009; for updates, visit www.mpib-berlin.mpg.de. **principal investigator; *post-doctoral fellow

\section{Research at the Center for Lifespan}

Psychology: Three Guiding Propositions

The following three propositions are meant to highlight essential features of the Center's research agenda. The propositions emphasize conceptual, theoretical, and methodological issues in the study of lifespan behavioral development, and thereby provide a general script for formulating research questions in more specific domains of interest.

Proposition 1: Lifespan Changes in the Individual's Behavior as Interactions Among Maturation, Learning, and Senescence

The general goal of developmental psychology is to identify mechanisms that generate invariance and variability, constancy and change in behavioral repertoires from infancy to old age. By identifying the commonalities, differences, and interrelations in the ontogeny of sensation, motor control, cognition, affect, and motivation, both within and across individuals, developmental psychologists attempt to arrive at more or less comprehensive theories of behavioral development. To provide explanations that qualify as psychological and developmental, the effects of agents external to the developing individual, such as parents' affect attunement, teachers' classroom behavior, or a state's retirement policies, need to be mapped onto mechanisms and organizational laws that operate and evolve within the developing 
person. Hence, developing individuals, rather than groups of individuals or domains of functioning within individuals, form the privileged system of analysis and explanation (e.g., Molenaar, 2008; Nesselroade, 1991).

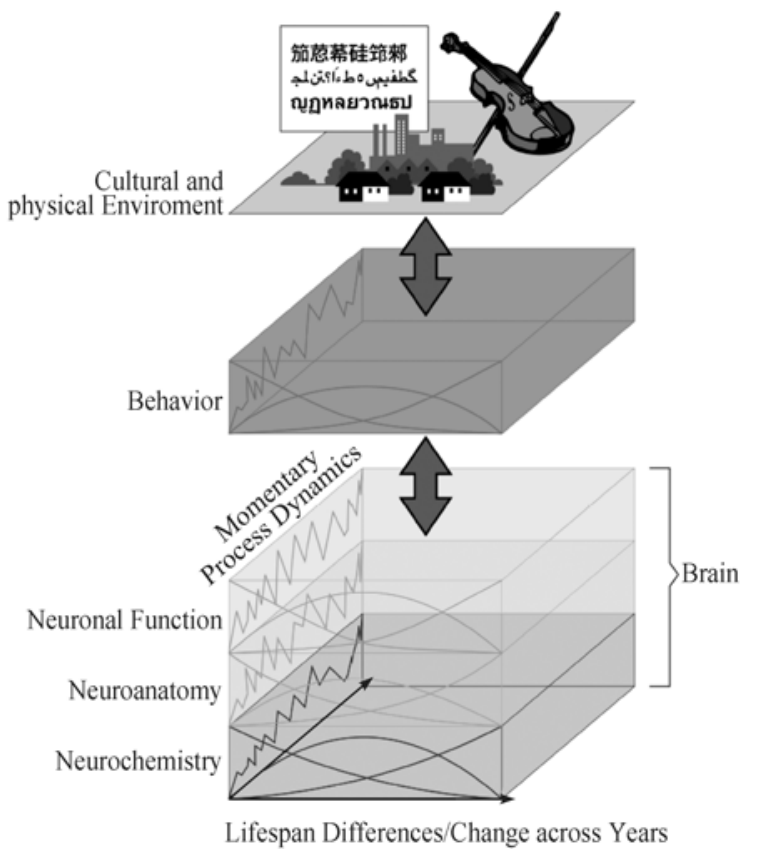

Figure 1. Environment and brain as antecedents and consequents of moment-to-moment variability and long-term changes in patterns of behavior. Lifespan changes in brain-behavior mappings are shaped by interactions among processes related to maturation, learning, and senescence. The identification of key players in the ontogeny of brain-behavior dynamics requires a coalition between formal tools for synthesis across levels of analysis and timescales, as well as empirical methods for studying variability and change in brain and behavior. Adapted from Lindenberger, Li, and Bäckman (2006).

Individuals organize their exchange with the physical and social environment through behavior (see Figure 1; cf. Lindenberger et al., 2006). On the one hand, the changing brain and the changing physical and cultural environment shape behavioral development. On the other hand, behavior alters both the brain and the environment. Hence, environment and brain act as antecedents, but also as consequents of moment-to-moment variability and long-term changes in patterns of behavior. The components of this system, brain, behavior, and environment, are constantly coupled and cannot be reduced onto each other, as they jointly condition an individual's life trajectory through recursive self-regulation.
In attempts to explain the age-graded evolution of this system, maturation and senescence denote the operation of age-graded brain mechanisms and their effects on changes in behavior, which are especially pronounced early and late in life. In addition, learning, at any point during ontogeny, denotes changes in brain states induced by behavior-environment interactions. Note, however, that maturation cannot take place without learning, and that learning cannot take place without maturation. Similarly, the ways in which senescence takes its toll on the brains of aging individuals depend on individuals' past and present learning and maturational histories. To complicate matters even more, processes commonly associated with maturation are not confined to early ontogeny, and processes related to senescence are not restricted to old and very old age (Raz et al., 2005). For instance, neurogenesis and synaptogenesis, as expressions of maturation, continue to exist in the adult and aging brain (Kempermann, 2005), and declines in dopaminergic neuromodulation, which indicate senescence-related changes in brain chemistry, commence in early adulthood (Bäckman, Nyberg, Lindenberger, Li, \& Farde, 2006; Li, Lindenberger, Nyberg, Heekeren, \& Bäckman, 2009). Thus, maturation, senescence, and learning mutually enrich and constrain each other throughout the lifespan, and must be understood and studied as interacting forces driving the brain-behaviorenvironment system. In this endeavor, psychologists occupy a central position because they possess a rich and adequate repertoire of experimental and methodological tools to describe and modify the organization of behavior.

\section{Proposition 2: Lifespan Theory and Methodology} Need to Integrate Evidence Across Domains of Functioning, Timescales, and Levels of Analysis

If the lifespan development of behavior is defined to originate from recursive interactions among maturation, learning, and senescence, with the developing individual as the privileged system of analysis, then developmental psychology is 
faced with three difficult integrative tasks. First, there is the need to integrate theorizing and research practice across functional domains to attain a comprehensive picture of individual development. For instance, sensorimotor and cognitive functioning are more interdependent in early childhood and old age than during middle portions of the lifespan, and developmental changes in either domain are better understood if studied in conjunction (Schaefer, Huxhold, \& Lindenberger, 2006). Similar observations can be made for many other domains of functioning whose changes generally have been studied in isolation, such as the ontogeny of social interaction and cognition, or of emotion regulation and motivational states. Empirically, dense multivariate time-series data are needed to assess short-term variability and long-term changes in across-domain dependencies (cf. Molenaar, 2008; Nesselroade, 1991; Siegler, 1994).

Second, there is a need to understand the mechanisms that link short-term variations to long-term change (S.-C. Li, Huxhold, \& Schmiedek, 2004; Lindenberger \& von Oertzen, 2006). Short-term variations are often reversible and transient, whereas long-term changes are often cumulative, progressive, and permanent. Establishing links between short-term variations and long-term changes is of eminent heuristic value, as it helps to identify mechanisms that drive development into different directions. For instance, aging cognitive systems show an increase in maladaptive moment-to-moment fluctuations, or decrease in processing robustness, at both behavioral and neuronal levels of analysis. These maladaptive changes may signal impending long-term changes in other characteristics of the system (see Figure 2; S.-C. Li, Lindenberger et al., 2004; Lövdén, Li, Shing, \& Lindenberger, 2006). In contrast, other forms of moment-to-moment variability indicate an individual's ability to bring a wide variety of different strategies to the task, and are positively related to long-term change in both childhood and old age.

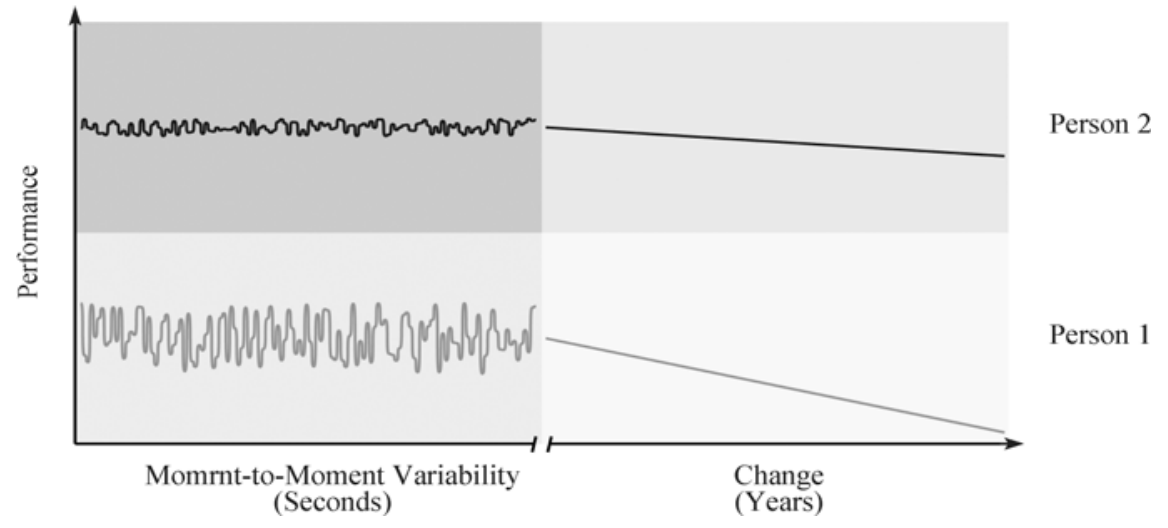

Figure 2. Example for predictions linking moment-to-moment variability to long-term change, and brain changes to behavioral changes. Senescent changes in neuromodulation lead to greater moment-to-moment fluctuations in neural signaling, enhance the prominence of background noise, reduce the distinctiveness of processing pathways and representations, and increase variability of cognitive performance. Aging individuals with greater moment-to-moment process fluctuations at a given point in time are expected to show greater subsequent longitudinal decline in mean levels of functioning than individuals who fluctuate less. Recent empirical evidence supports this prediction (Lövdén et al., 2007). Adapted from Lindenberger, Li, and Bäckman (2006).

Third, to arrive at mechanistic explanations of behavioral change, there is the need to integrate behavioral and neuronal levels of analysis. At any given point in the lifespan, one-to-one mappings between brain states and behavioral states are the exception, rather than the rule, as the brain generally offers more than one implementation of an adaptive behavioral outcome (S.-C. Li \& Lindenberger, 2002). Therefore, ontogenetic changes in behavioral repertoires are accompanied 
by continuous changes in multiple brain-behavior mappings. Some of these re-mapping gradients may be relatively universal and age-graded, whereas others may be more variable, reflecting genetic differences, person-specific learning histories, the path-dependent nature of developmental dynamics, or a combination of the three. The resulting picture underscores the diversity and malleability of the organization of brain and behavior, as well as the constraints on diversity and malleability brought about by (a) universal age-graded mechanisms associated with maturation and senescence, (b) general laws of neuronal and behavioral organization, and (c) cultural-social as well as physical regularities of the environment (Baltes et al., 2006; cf. Dehaene \& Cohen, 2007; Li, 2003).

In summary, developmental psychology needs theory and methodology apt to integrate (a) multiple domains of functioning, (b) multiple timescales, and (c) multiple levels of analysis. In recent years, the Center for Lifespan Psychology has relied on two methodologies that seem well suited to these conceptual demands. First, random coefficient modeling (RCM), latent growth curve modeling (LGCM), and related statistical techniques have served as versatile tools for the analysis of multivariate data with nested time structures such as trials, blocks of trials, days, weeks, and years. Dynamic extensions of these methods, such as the dual-change score model introduced by McArdle and Hamagami (2001), permit the investigation of directed lead-lag hypotheses with longitudinal panel data (for examples, see Ghisletta \& Lindenberger, 2003; Lövdén, Li et al., 2006). Second, neurocomputational modeling, such as the neurocomputational theory of neuromodulation of cognitive aging proposed by Shu-Chen $\mathrm{Li}$ and colleagues (e.g., S,-C. Li, 2002; S.-C. Li \& Lindenberger, 1999; S.-C. Li, Lindenberger, \& Sikström, 2001; S.-C. Li \& Sikström, 2002; S.-C. Li, von Oertzen, \& Lindenberger, 2006) has facilitated conceptual integration of empirical findings and concepts from a wide range of behavioral and neuronal research traditions, and provides a theoretical basis for major portions of the Center's research program.

Proposition 3: The Exploration of Age-Graded Differences in Behavioral Plasticity is a Powerful Tool for Identifying Mechanisms of Development

Behavioral plasticity, or the alteration of developmental trajectories through experience, is a precious phenomenon. This statement holds both from scientific and societal perspectives (Hertzog, Kramer, Wilson, \& Lindenberger, 2009). Scientifically, inquiries into the plasticity of human behavior are a rich source of developmental information. Through the assessment of "changes in change," they offer the promise to observe the operation and proximal consequences of developmental mechanisms. In particular, cognitive intervention studies, in which research participants of different ages are instructed and trained to perform one or more cognitive tasks, come with important validity benefits such as (a) an increase in experimental control; (b) the identification of age differences near asymptotic performance levels; and (c) the assessment of transfer and maintenance effects. If neurochemical, neuroanatomical, or neurofunctional imaging measures are assessed before, during, and after training, intervention studies also offer new insights into relations between behavioral and neuronal levels of plasticity. Thus, by partly taking control over behavior-environment interactions, the mechanisms of learning can be studied in the context of maturation and senescence. When longitudinal information is available, intervention studies bridge the gap between short-term alterations in performance and long-term developmental trajectories (e.g. Singer, Lindenberger, \& Baltes, 2003; see below).

From the larger perspective of societal evolution, cognitive intervention studies explore the range of possible development, or what could be possible in principle if conditions were different. 
The resulting knowledge about the plasticity of developmental trajectories is essential for improving human welfare (Hertzog et al., 2009). Hence, investigations of age changes in the plasticity of development carry the potential to explain and ameliorate human development. For these reasons, age-comparative intervention studies with a focus on behavioral and neuronal manifestations of plasticity are the foundation stone of empirical research at the Center for Lifespan Psychology.

Overview of Research Projects at the Center for Lifespan Psychology

The research at the Center for Lifespan Psychology is currently structured into eight research projects, each with a team of scientific investigators (see Table 1). The research activities pursued in these projects cover a wide array of developmental topics. To provide a few examples for illustration, recent studies have addressed the following questions: (a) How do relations between body and mind change from childhood to adulthood, and from adulthood to old age? (b) How and why do functions such as intelligence and memory vary within and across individuals, and how and why do they change with age? (c) How and to what end do individuals acquire and maintain a sense of personal control? How do they plan and manage their lives? (d) How do aging individuals cope with rapid technological change, and how can human engineering technologies facilitate the transition to old age? (e) How do young children learn to coordinate their behavior with others, and how does interpersonal action coordination affect social and cognitive development? (f) How do age-graded changes in brain resources modulate genetic effects on cognitive performance? In addition to these research projects, the Center also hosts the independent junior research group of Martin Lövdén, who won the Sofja Kovalevskaja Award of the Alexander von Humboldt Foundation in 2006. In collaboration with colleagues from the
Center, Martin Lövdén is using the four-year research funds associated with this award to investigate adult age differences in the plasticity of brain and behavior, with a special focus on spatial navigation and working memory, including their relations to medio-temporal and prefrontal brain regions. The reminder of this article is restricted to four projects, with an eye on the Center's guiding propositions.

\section{Research Project 1: Neuromodulation of Lifespan Cognition}

Cognitive development across the lifespan consists in age-graded, co-constructive interactions between cultural and biological systems of influence ( $\mathrm{Li}, 2003)$. The brain implements these interactions at the individual level. Human brains have about one hundred billion neurons, and most of them are highly interconnected. Neurons release neurotransmitters for communication. Neurotransmitters shape the dynamics of neural networks in the course of development, and modulate behavior from moment to moment in the service of goal-directed behavior (Bäckman et al., 2006; Li et al., 2009).

Fundamental aspects of cognition such as processing speed, processing robustness, attention, working memory, episodic memory, and reinforcement learning increase monotonically from childhood to early adulthood and decrease from early adulthood to late adulthood, with accelerated decline in old age ( $\mathrm{Li}$, Lindenberger, Hommel, Aschersleben, Prinz, \& Baltes, 2004). These changes in behavior are paralleled by neurochemical, neuroanatomical, and functional changes in the brain (Lindenberger et al., 2006). The central goal of this project is to understand how maturational and senescent changes in neurotransmitter systems contribute to neuronal and behavioral development across the lifespan. For this purpose, the project uses a large and integrated array of conceptual tools and empirical paradigms, ranging from neurocomputational studies for theory development over genetically 
informed behavioral studies for understanding the relations between neurally relevant genotypes and cognitive phenotypes to genomic and pharmacological imaging studies for investigating developmental changes in brain-behavior relations, and the individual differences therein.
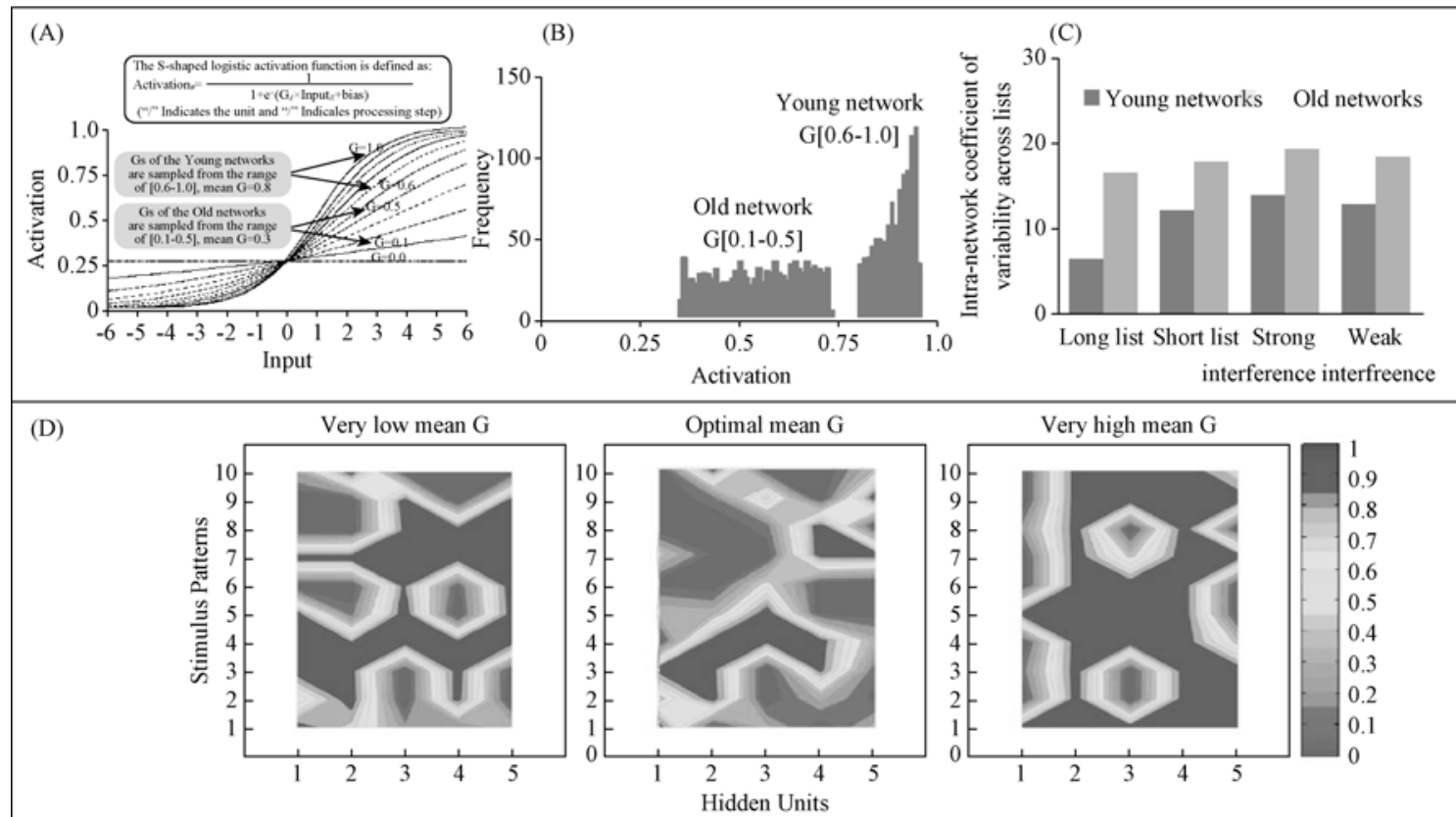

(E)



Figure 3. Modeling the effects of depleted, optimal, and excessive dopamine levels on the distinctiveness of cortical representations and cognitive performance. (A) Simulating aging-related losses in dopaminergic neuromodulation by reducing stochastic gain tuning. Reduced gain tuning increases (B) random activation variability and (C) performance variability in simulated old networks (adapted from Li, Lindenberger, and Sikström, 2001). Stochastic gain tuning captures the inverted-U function relating DA modulation and functional outcomes of (D) distinctiveness of activation patterns and memory performance (adapted from Li and Sikström, 2002, Neuroscience and Biobehavioral Reviews, 26, 795-808).

\section{A Computational Theory of Neuromodulation of}

\section{Cognitive Aging}

A main aspect of this project focuses on the role of neuromodulation in cognitive aging. The efficacy of neurotransmitter systems wanes during normal aging (Bäckman et al., 2006; Li et al., 2009). In our neurocomputational work (Li \& Lindenberger, 1999; Li, Lindenberger, \& Sikström, 2001), we capture aging-related declines in dopaminergic neuromodulation by stochastically attenuating the gain control $(G)$ of the sigmoidal activation function modeling presynaptic to postsynaptic transfer (see Figure 3). With large inputs, reducing the slope of the activation function leads to increased within-network random activation variability. This, in turn, results in increased performance variability in simulated aging networks with attenuated $\mathrm{G}$. If $\mathrm{G}$ is increased beyond the optimum to excessive values, activation variability depends critically on the amplitudes of the inputs because information transfer is governed by a step function. Hence, and in line with empirical findings, stochastic $G$ tuning predicts an inverted-U function between dopaminergic neuromodulation and cognitive performance.

\section{Genomic Approaches to Neuromodulation of Cognitive Aging}

In collaboration with the Berlin Neuroimaging Center, we launched a large-scale empirical study combining genomic, pharmacological, and brain 
imaging approaches to investigate the triadic relation between adult age, dopaminergic neuromodulation, and cognition ${ }^{*}$. The major aims of the neuromodulation of cognitive aging study are to investigate dopaminergic neuromodulatory efficiency in relation to (a) age, (b) dopaminerelevant genetic polymorphisms such as the Catechol-O-Methyltransferase (COMT) gene (Goldberg \& Weinberger, 2004), and (c) pharmacological intervention with a dopamine agonist. The study consists of two parts, a large-scale behavioral assessment, followed by a pharmaco-genetic imaging experiment. Currently about 800 of younger adults aged 20-30 years and 800 older adults aged $60-70$ years have been genotyped and have participated in the behavioral assessment, which covers a wide range of cognitive functions with a special emphasis on perceptual decision making, working memory, and episodic memory.

To provide an illustration of the general approach, we summarize our current findings of the COMT gene's effect on working memory performance in old age. COMT enzymatic activity results in degradation of dopamine, influencing endogenous dopamine levels in prefrontal cortex. A common polymorphism of the COMT gene is associated with individual differences in intrinsic dopamine levels in the human prefrontal cortex. Specifically, COMT enzymatic activity is three to four times higher in Val than in Met homozygotes. The lower enzymatic activity among Met carriers leads to less frontal dopamine degradation and hence greater dopamine availability at the receptors. Given that dopamine levels decrease with advancing adult age and that the function relating dopamine signaling to cognitive performance is assumed to be nonlinear, we

\footnotetext{
* This part of the project is carried out in collaboration with Lars Bäckman (Karolinska Institute, Stockholm), Hauke Heekeren (MPI for Human Development, Berlin, and MPI for Cognitive and Brain Sciences, Leipzig), Lars Nyberg (University of Umeå, Sweden), and Arno Villringer (Department of Neurology, Charité, Berlin).
}

predicted that performance differences between Val homozygotes and Met carriers would be more pronounced among older adults than among younger adults (see Figure 4; Lindenberger et al., 2008). Recent data from this project support this prediction, showing that older individuals show particularly low performance on tasks taxing executive control and working memory when they are homozygotic for the Val allele of the COMT gene (Figure 5; Nagel et al., 2008).

Similarly, another study from the same project also showed that effects of the brain derived neurotrophic factor (BDNF) gene on episodic memory is apparent in older but not in younger samples ( $\mathrm{Li}$ et al., in press).

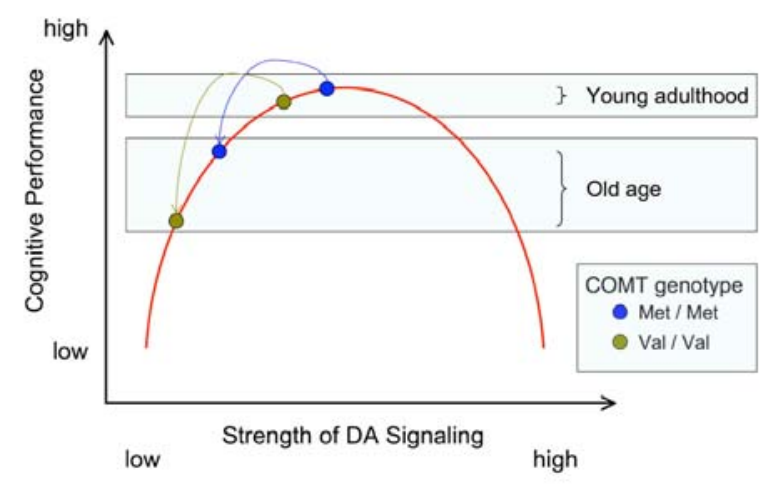

Figure 4. Function relating the strength of frontal DA signaling to cognitive performance. The inverted $U$ shape of the curve implies that performance differences between Met and Val carriers of the COMT gene are greater for older adults than for younger adults, reflecting the decline in dopaminergic neuromodulation with advancing adult age (adapted from Nagel et al., 2008, Frontiers in Human Neuroscience, 2, $1-8)$.

\section{Research Project 2: Intra-Person Dynamics Across the Lifespan}

The unifying theme of this project is to develop theories and research designs that articulate behavioral and neuronal development across timescales and levels of analysis. This emphasis requires a drastic increase in observation density within individuals, following Cattell's (1952) plea to gather multivariate observations not only within occasions across persons, but also within persons across occasions. 


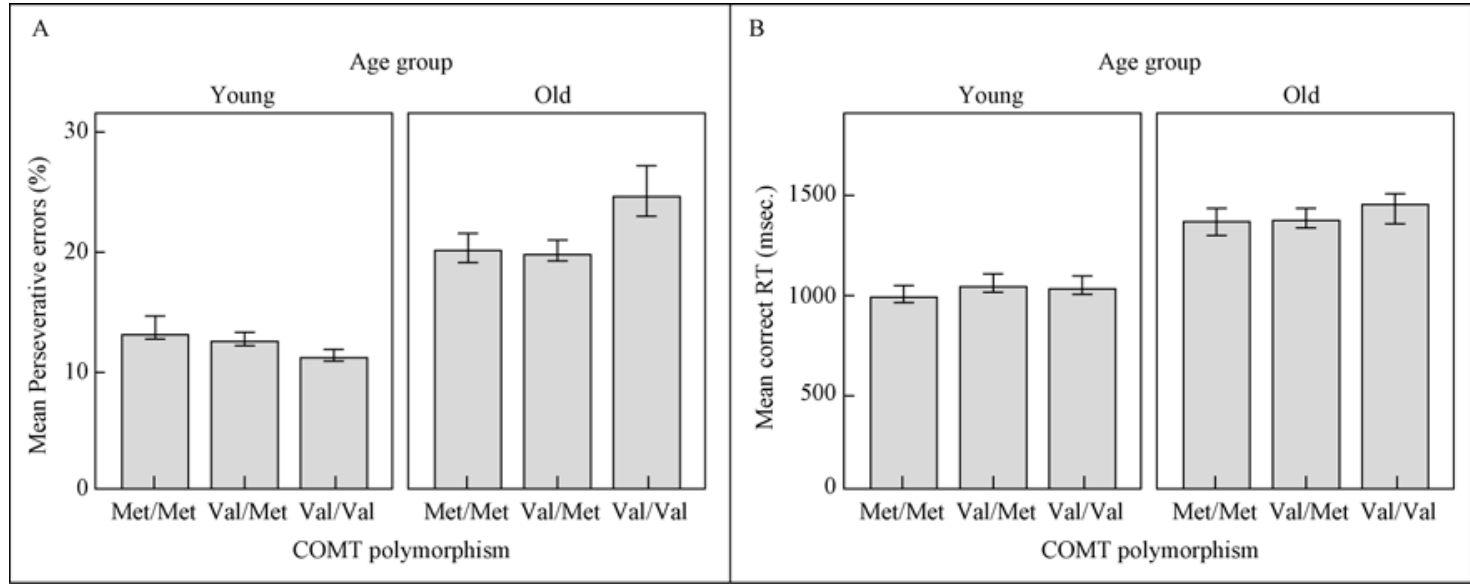

Figure 5. Genetic and age effects on executive functions. The effects of allelic variation in the COMT gene on (A) percent of perseverative errors measured by the Wisconsin Card Sorting Task and (B) reaction times of working memory performance (adapted from Nagel et al., 2008, Frontiers in Neuroscience, 2, 1-8).

\section{Types of Intra-Person Variability}

In examining relations between short-term variability and long-term age changes or age differences, behavioral variability can be classified by its function (S.-C. Li, Huxhold, \& Schmiedek, 2004). One may distinguish among plasticity, diversity, adaptability, fluctuation, and temporal coupling. Plasticity, in this context, refers to various forms of adaptive performance alterations, such as learning induced by instruction, practice, and training (cf. Baltes \& Kliegl, 1992; Singer et al., 2003). Diversity refers to variations in responses to environmental demands, such as exploration of behavioral strategies during initial phases of complex skill acquisition (e.g., Lautrey, 2003; Siegler, 1994). Adaptability indicates an individual's ability to regain earlier functional levels after perturbations arising from either internal processing fluctuations (e.g., attention slips) or changes in the external environment (e.g., more demanding tasks). Processing fluctuation, or lack of processing robustness (e.g., S.-C. Li, Huxhold, \& Schmiedek, 2004; S.-C. Li, Lindenberger et al., 2004), reflects stochastic fluctuations around a modal response. Processing fluctuations can be observed more easily when the functional value of other forms of variability is low to begin with, as is often the case for standard reaction time tasks, or when the functional values has been reduced, as is the case when individuals have consolidated the use of a particular strategy and are operating near maximum levels of functioning. Finally, temporal coupling refers to associations between two or more forms of processing within or across domains of functioning, such as concurrent covariation, lead-lag relations, and synchronization, at identical, different, or hierarchically nested timescales.

Exploring Age Differences in Fluctuations and Across-Domain Couplings: The 45-Days Study

A first micro-longitudinal study covering 45 daily measurement occasions compared adult age differences in intra-person fluctuations in four domains of functioning: postural control, spatial working memory, positive and negative affect, and task-specific motivation. Eighteen young adults (20 to 30 years of age) and 19 older adults (70 to 80 years of age) participated in the study across nine weeks. With respect to cognitive and sensorimotor functions, older adults showed greater intra-person fluctuations than younger adults. For instance, older adults' reaction times in a spatial working memory task had a higher mean and a wider distribution than younger adults' reaction times, and varied more from day to day in older adults than in younger adults.

The study also examined whether intra-person fluctuations in sensorimotor function (e.g., 




Figure 6. Adult age differences and similarities in working memory plasticity: Practice gains and transfer. Net effect sizes (practice group minus control group) of reaction times for practice gains on regular and difficult versions of a spatial 2-back working memory task, and transfer effects in near transfer tasks, that is, a more demanding spatial 3-back task and numerical versions of the 2-back and 3-back tasks. Effect sizes reflect gains in performance speed. Both younger and older adults improved considerably both on practiced tasks, and on transfer tasks. Adapted from Li, Schmiedek, Huxhold, Röcke, Smith, and Lindenberger (2008).

postural control) and cognitive function (e.g., spatial working memory) are more strongly coupled in older than in younger adults. Individuals who fluctuated more in postural control (i.e., older males) showed stronger couplings between daily fluctuations in postural control and daily fluctuation in working memory than individuals who fluctuated less in postural control (Huxhold, 2007). In contrast, with respect to emotional functions, older adults showed significantly less day-to-day fluctuation in positive and negative affect than younger adults (Röcke, Li, \& Smith, in press). This pattern is consistent with the hypothesis that emotion regulation improves with advancing adult age (Carstensen, 1993), but alternative explanations such as age-linked differences in social contexts or arousal cannot be ruled out.

Furthermore, this study also gave us the opportunity to investigate adult age differences in the plasticity of cognitive performance, maintenance of training gain, and transfer of training effects. Specifically, after 45-day of extensive practice with spatial working memory tasks, both younger and older adults showed substantive improvements on practiced tasks as well as transfer to non-trained tasks with similar processing demands but different content or higher difficulty (see Figure 6; Li, Schmiedek, Huxhold, Röcke, Smith, \& Lindenberger, 2008). These effects were maintained for several months in younger but decreased in older adults, pointing to age-related decline in the ability to maintain skilled working memory performance. In a different but related analysis of the same spatial working memory tasks, we also found that older adults were more likely to commit confusion errors in working memory performance than younger adults (Schmiedek, Li, \& Lindenberger, 2009).

Comparing Within-Person with Between-Person Structures of Cognitive Abilities: The 100-Days Study

After the first initial 45-day study, the Intra-Person Dynamics conducted a second and larger scale study (covering 100-day of assessments) to more thoroughly investigate the differences and the commonalities between covariance structures of intellectual abilities measured across individuals at a given occasion 
and across occasions within a given individual. Most existing research on intellectual abilities assumes that covariance structures based on interindividual differences generalize to intraperson structures. However, as Raymond B. Cattell (1952), Jacques Lautrey (2003), John Nesselroade (1991), Peter Molenaar (2008), and others have argued for a long time, differences between intraperson and inter-person structures are perfectly possible. Conceptually, the malleability of functional organization at both behavioral and neuronal levels and the diversity of developmental trajectories and life experiences render any strict congruence between intra-person and inter-person structures unlikely (Li \& Lindenberger, 2002).

One-hundred and one younger adults aged 20-31 years and 103 older adults aged $65-80$ years participated in 100 daily sessions, working each day on a set of twelve cognitive tasks comprising perceptual speed, episodic memory, and working memory. Self-report measures of affect, motivation, and mood were also assessed on a daily basis. In addition, all participants completed comprehensive pretests and posttests, with baseline measures of cognitive abilities, and transfer tasks for the practiced abilities. In subsamples of 25 younger and 19 older participants, brain-related measures were taken at pretest and posttest, including structural magnetic resonance imaging, functional magnetic resonance imaging, and electroencephalographic recordings. The study was preceded by extensive pilot work to validate the measures and examine their multivariate structure (e.g., Schmiedek, Hildebrandt, Lövdén, Wilhelm, \& Lindenberger, in press).

The data of this study will, for the first time, permit researchers to systematically examine differences and commonalities between covariance structures of intellectual abilities measured either (a) across individuals at a given occasion or (b) across occasions within a given individual. Most existing research and theorizing on cognitive abilities assumes that covariance structures based on between-person differences generalize to intra-person structures (e.g., the ergodicity assumption; cf. Molenaar, 2008). Surprisingly, it is not yet known whether ability structures representing between-person differences are good approximations of ability structures representing day-to-day variations in cognitive performance within individuals. To find out about this issue, developmental researchers need to abandon a quid-pro-quo research practice, in which betweenperson differences stand in for within-person variations (cf. Lindenberger \& Oertzen, 2006).

To complicate matters, the degree of congruence between within-person structures and between-person structures may vary by age. For instance, given that alterations in cognitive functioning among older adults reflect variable combinations of age-related, pathology-related, and death-related mechanisms (e.g., Ghisletta, McArdle, \& Lindenberger, 2006; cf. Sliwinski, Lipton, Buschke, \& Stewart, 1996), the average similarity of the within-person structures of old adults to the between-person structures of old adults may be smaller than the average similarity of the within-person structures of young adults to the between-person structure of young adults. For related reasons, the study will also shed new light on the dedifferentiation hypothesis of old-age intelligence (cf. Lövdén \& Lindenberger, 2005). According to this hypothesis, increasing correlations among cognitive abilities with advancing age reflect the operation of domaingeneral resource limitations. The critical question here is whether earlier observations of increasing correlations among cognitive abilities with advancing age, when assessed across persons (e.g., S.-C. Li et al., 2004), are matched by increasing correlations among cognitive abilities with advancing age, when assessed within persons across days. Extending this question to the neuronal level of analysis, we can ask whether older individuals who show low levels of average performance and high correlations among different cognitive abilities tend to be those who show 
diffuse cortical activation patterns relative to older individuals with high average levels of performance and low correlations among cognitive abilities.

\section{Project 3: Cognitive and Neuronal Dynamics of Memory across the Lifespan}

Another project at the Center focuses specifically on cognitive and neuronal dynamics of memory across the lifespan. The overarching objective of the project "Cognitive and Neuronal Dynamics of Memory across the Lifespan (CONMEM)" is to provide mechanistic and process- oriented explanations for developmental changes in memory functions. Memory processing in the brain is distributed and carried out in parallel involving several cortical and sub-cortical regions, including the prefrontal (PFC), mediotemporal (MTL), and parietal regions, among others (see Simons \& Spiers, 2003 for review).

The basic conceptual framework of the CONMEM project holds that maturational, experience-dependent, and senescent forces express their influences on the varying contribution of associative and strategic components during memory encoding, consolidation, and retrieval (cf., Shing, Werkle- Bergner, Li, \& Lindenberger, 2008; Shing, Werkle-Bergner, Brehmer, Müller, Li, \& Lindenberger, in press; Werkle-Bergner, Müller, Li, $\&$ Lindenberger, 2006). The associative component of memory refers to mechanisms during encoding, consolidation, and retrieval that bind different aspects of an event into a cohesive memory representation. The associative component can be linked to the functioning of the MTL (especially the hippocampus) and posterior association areas. It is assumed that synchronized activity within and between neuronal networks acts as a binding mechanism in the service of episodic memory (e.g., Zimmer, Mecklinger, Lindenberger, 2006). The strategic component, on the other hand, contributes to memory through selective elaboration, organization, and search for relations among features. Strategic processes may be self-activated spontaneously or elicited by instruction. The functioning of the strategic component is closely related to attentional and control mechanisms mainly supported by PFC regions. As both components rely on partially overlapping and interactive neuronal circuitries, the functioning of both components is highly interdependent, posing an intricate challenge for empirical investigations (e.g., Werkle-Bergner, Müller, Li, \& Lindenberger, 2006).

With respect to episodic memory development, we expect lifespan dissociations between strategic and associative memory components (Shing, Werkle-Bergner, Li, Lindenberger, 2008; Werkle- Bergner, Müller, Li, \& Lindenberger, 2006). We assume that the protracted maturation of prefrontal regions and associated neural pathways limits the efficiency of the strategic component in children relative to young adults. In contrast, we assume that the associative component, which primarily involves the MTL, is fully functional by middle childhood. For old age, the theory postulates deficiencies in both components relative to early adulthood, reflecting senescent alterations in PFC and MTL regions of the brain and related neuronal circuits. The predicted lifespan dissociation between the two components offers an overarching framework for lifespan studies, and provides a starting point for identifying mechanisms of lifespan changes in various forms of memory, including episodic memory and working memory.

\section{Lifespan Age Differences in Episodic Memory Plasticity}

The predicted lifespan age differences are supported by a series of our studies ${ }^{*}$. In an early study, lifespan age differences in episodic memory plasticity were investigated in an initial multisession memory training study involving younger children (9-10 years, $n=23$ ), older children

\footnotetext{
* This part of the project is partially funded by a research grant from the Deutsche Forschungsgemeinschaft (FOR 448, Cooperative research group, "Binding: Functional architecture, neuronal correlates, and ontogeny”).
} 


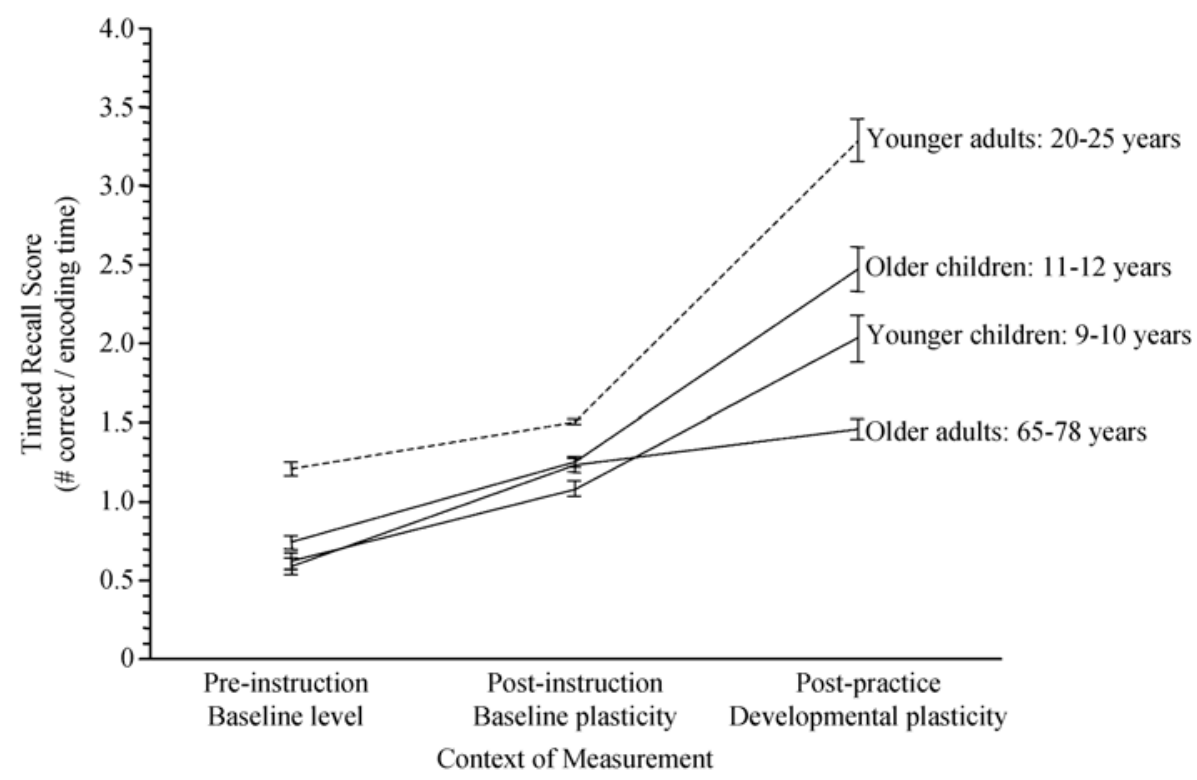

Figure 7. Plasticity of episodic memory performance from middle childhood to old age. Age differences before instruction, after initial instruction, and after multi-session practice and training. Post-instruction scores for younger adults cannot be interpreted because of ceiling effects; all other data points are interpretable. Adapted from Brehmer et al. (2007).

(11-12 years, $n=27)$, younger adults $(20-25$ years, $n=29)$, and older adults (65-78 years, $n=29$;

Brehmer, Li, Müller, von Oertzen, \& Lindenberger, 2007). Participants in all age groups were instructed and trained in a simplified variant of the Method of Loci, an imagery-based mnemonic strategy (Baltes \& Kliegl, 1992). Thus, the study provided, for the first time, a direct comparison of plasticity in episodic memory performance from middle childhood to old age.

The main results are shown in Figure 7. Individuals in all age groups benefited from mnemonic instruction and training. At the same time, substantial age differences in gains were observed. Older adults showed instruction-related performance gains, but they did not profit much from further training and practice. In contrast, younger children initially showed smaller instruction-related performance gains but considerably larger practice-related gains than older adults. The observed plasticity advantage of middle childhood over late adulthood supports predictions on lifespan changes in behavioral plasticity (cf. Lindenberger, 2001). To examine lifespan age differences in the maintenance of skilled memory performance, a longitudinal follow-up study was carried out 11 months after termination of the first study (Brehmer et al., 2008). Whereas both younger and older adults were able to maintain their level of performance over the 11-month period, younger and older children actually improved their memory performance beyond originally attained levels. Taken together, episodic memory plasticity in middle and late childhood reflects a powerful coalition between learning and maturation, allowing children to improve their level of skill in the absence of further practice.

Lifespan Dissociation of Strategic and Associative Memory Components

In a more recent study ${ }^{*}$, demands on associative and strategic components were systematically manipulated with an associative recognition memory task in a within-person repeated-measures design (Shing, Werkle-Bergner, Li, \& Lindenberger, 2008). Fourty-three children, 43 teenagers, 42 younger adults, and 42 older adults were presented with lists of word pairs, and

\footnotetext{
* This part of the project is partially funded by a research grant from the Deutsche Forschungsgemeinschaft (FOR 448, Cooperative research group, "Binding: Functional architecture, neuronal correlates, and ontogeny”).
} 


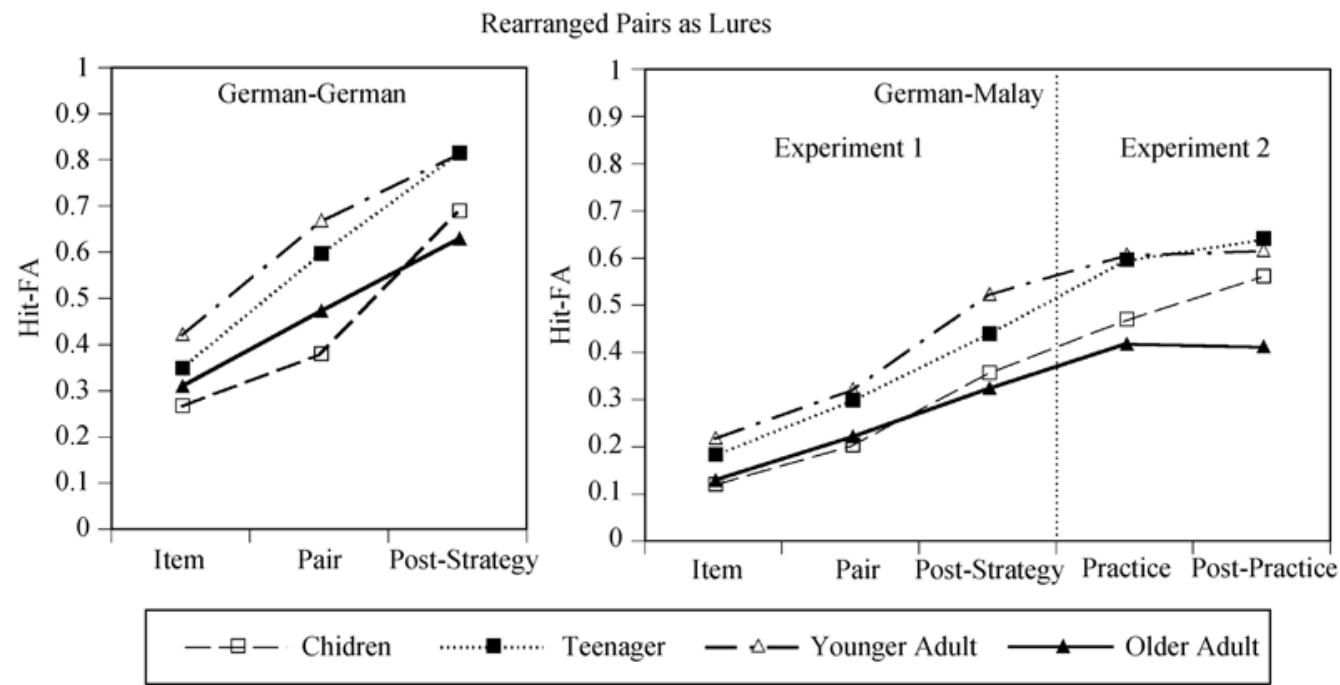

Figure 8. Empirical support for the two-component model of episodic memory development across the lifespan. In two multi-session experiments, memory for word pairs was probed with a recognition paradigm. Panel A displays data for the associatively less demanding German-German (GG) condition, Panel B for the associatively more demanding German-Malay (GM) condition. The strategic component was manipulated by instruction and subsequent practice. Memory performance refers to correctly recognized pairs (hits) minus erroneously recognized lure pairs (false alarms). Here, the lure pairs consist of words that had been separately presented during encoding. As predicted, children overcame their initial strategy deficit through strategic instruction and subsequent practice, and eventually surpassed older adults, demonstrating the efficacy of their associative component. Dissertations Yee Lee Shing and Markus Werkle-Bergner. Adapted from Shing, Werkle-Bergner, Li, and Lindenberger (2008).

were subsequently tested for their associative memory. Associative demand was varied by manipulating the type of word pair to be studied (German-German 'GG' versus German-Malay 'GM'), and strategic involvement was varied by encoding instructions that either emphasized (a) incidental item encoding, (b) intentional pair encoding, or (c) elaborative strategic encoding. A practice-based follow-up study for the GM condition was conducted to induce further improvements in participants' performance in this condition. Results of this study are consistent with the two-component model of episodic memory development across the lifespan (see Figure 8). With strategic instruction and practice, children improved more than older adults in forming memory associations, demonstrating their latent potential for associative binding after overcoming their difficulty in implementing and effectively using a mnemonic strategy. This finding is in line with the hypothesis that the associative component of episodic memory matures early in childhood. Older adults, in contrast, did not benefit as much as the children from instruction and practice in the mnemonic strategy. Relative to the other three groups, older adults' performance gains were especially small in the associatively demanding GM condition, supporting the hypothesis that associative binding deteriorates with advancing adult age.

\section{Research Project 4: Sensorimotor-Cognitive Couplings}

Whereas the projects reviewed above focus mainly on lifespan development of cognitive functions and their neurobiological correlates, a fourth project at the Center investigates lifespan changes in the interactions between sensorimotor and cognitive aspects of behavior (Schäfer, Huxhold, \& Lindenberger, 2006). Everyday life often requires the integration of multiple sensory inputs and concurrent coordination of sensorimotor and cognitive demands. Examples are walking while trying to memorize a shopping list, maintaining one's balance on a bus while trying to read an advertisement, or trying to remember the way to a friend's house while driving in the hectic morning traffic. Everyday 
observation further suggests that older adults, and young children, need to invest more attention into sensorimotor aspects of their behavior than teenagers and young adults. For example, when facing an obstacle on a narrow path, older adults may tend to stop talking and resume their conversations after the obstacle has been overcome, whereas the same obstacle will affect younger adults' conversation to a lesser extent. How do individuals of different ages adapt to multiple sensorimotor and cognitive demands? How does the interaction between sensorimotor and cognitive dimensions of behavior change across the lifespan? This project seeks to provide answers to these questions by studying sensorimotor and cognitive behavior in multiple-task settings with a high degree of everyday validity. A related goal of the project is to propose and test criteria for effective technological assistance in old age.

\section{Age-Comparative Dual-Task Studies in the}

\section{Domains of Walking and Balance}

In earlier work, we showed that older adults invest considerable cognitive resources to compensate for the decreased efficiencies of their sensorimotor functions, leading to higher dual-task costs in situations in which walking on a narrow track was combined with the cognitive task of memorizing word lists (Lindenberger, Marsiske, \& Baltes, 2000). In another study, we found that older men profited from the possibility to hold on to a handrail while finding their way in a virtual museum, while there was no difference in way-finding performance for younger men walking with or without support (see Figure 9; Lövdén, Schellenbach, Grossman-Hutter, Krüger, \& Lindenberger, 2005). In this study, we also found that walking with navigation load increased older adults', but not younger adults', trunk-angle variability.

These studies point to greater dual-task costs in older adults, presumably due to increased demands of motor control on cognitive control and reductions in cognitive control capacity. However,

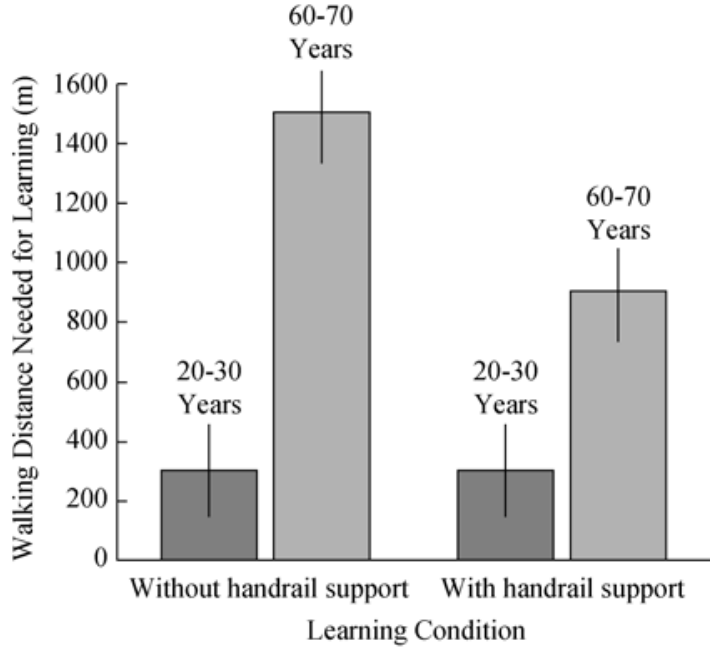

Figure 9. Adult age differences in way-finding (spatial navigation) performance are shaped by sensorimotor demands. Bars display the mean distance covered to criterion as a function of age group (young and older adults) and walking demand (with or without handrail support). Provision of a handrail does not alter the way-finding performance of the younger adults, but considerably improves the way-finding performance of the older adults. Adapted from Lövdén et al. (2005).

cognitive-sensorimotor dual-task situations do not always lead to performance reductions. Accumulating evidence points to a U-shaped relationship between motor control and difficulty of concurrent cognitive activities during balance. That is, motor control appears to increase in efficiency relative to motor performance under single-task (motor only) conditions if an easy cognitive task needs to be performed at the same time, and to decrease again as the cognitive task gets more difficult. Presumably, cognitive activities of lower difficulty promote an external focus of attention that allow the motor system to self-organize and smoothly execute movement. In contrast, higher levels of cognitive task difficulty may hamper motor control performance through cross-domain resource competition, much like those found in the walking studies reported above. The point at which performance improvements due to the first process is surpassed by decrements induced by the second process in a given individual should be predictable by the individual's sensorimotor and cognitive resources, and the demands of motor control on cognitive control (dual-process model of the interactions 
between cognition and sensorimotor functioning). In an early study investigating the non-monotonic relation between cognitive load and postural control, Huxhold, Li, Schmiedek, and Lindenberger (2006) found that older adults showed performance decrements in balance while standing at lower levels of concurrent cognitive task difficulty than young adults, who were able to further reduce their body sway while standing even while working on very difficult cognitive tasks.

Recently, Lövdén, Schaefer, Pohlmeyer, and Lindenberger (2008) extended the validity of the dual-process account proposed by Huxhold et al. (2006) to the functional domain of walking. We used the n-back task, a standard measure of working memory that allows for parametric variation in task difficulty, in 32 younger adults (mean age of 25 years) and 32 older adults (mean age of 74 years) who were asked to walk on a treadmill at self-selected speed. Effects of age and age by working memory load, but not dual-tasking, were found for cognitive performance. Stride-tostride variability was reduced when participants simultaneously performed an easy working memory task (1-back) as compared to walking without a working-memory task. Further increments in working memory load (i.e., from 1-back up to 4-back) caused reductions in the variability, but not in the means, of stride time and stride length in younger adults, but not in older adults. In line with these observations, a principal component analysis based on the gait patterns of the two age groups mentioned above and an additional group of older adults between 60 and 70 years of age indicated a U-shaped pattern for residual whole-body variability in the oldest age group (Verrel, Lövdén, Schellenbach, Schaefer, \& Lindenberger, 2009). The principal component analysis subtracts the regular from the irregular components of whole body motion, and the residual variance can be interpreted as an index of gait irregularity. Parametrically increasing working memory load from 1-back to 4-back led to age-differential effects, with gait patterns becoming more regular in the 20 to 30 year olds, less regular in the 70 to 80 year olds, and showing no significant effects in the 60 to 70 year olds. We conclude that normal aging is associated with alterations in the trade-offs between two continuous control processes involving positive effects of external focus of attention and negative effects of resource competition, respectively.

Our on-going work on the relation between body movement and cognitive load also includes children. In a recent study, Schaefer, Lövdén, Wieckhorst, and Lindenberger (in press) found that children, similar to older adults, tend to increase their gait variability with increasing working memory load. In the cognitive domain, however, both children's and young adults' working memory performance was actually higher when walking than when sitting on a chair, but only when individuals were walking on the treadmill at their preferred speed. Cognitive performance did not improve when the treadmill had a fixed speed of $2.5 \mathrm{~km} / \mathrm{h}$, suggesting that the adjustment of one's walking speed to the speed of the treadmill may require attentional resources. Thus, at least in children and young adults, cognitive performance may benefit from periodic forms of body movement such as continuous walking across a wide range of difficulty levels.

The finding that cognitive sensorimotor dual-task situations do not always lead to dual-task costs in both task domains was further supported by a study by Schaefer, Krampe, Lindenberger, and Baltes (2008). In this study, children and young adults balanced on a special balance device, the ankle-disc board, while concurrently memorizing word lists or working on a working memory task. Balance performance was measured by dynamic posturography on a force platform, which measures participants' stability on the ankle-disc board at any given point in time. Both children and young adults showed performance decrements, that is, dual-task costs, in the cognitive domain, and young adults also increased their body sway on the ankle-disc board when 
concurrently working on a demanding cognitive task. In contrast, children swayed less when concurrently performing a cognitive task, resulting in negative dual-task costs, or dual-task gains. Children continued to show performance improvements in the balance domain under dual-task conditions even when participants were instructed to focus their attention more strongly on the cognitive task. It is tempting to interpret the children's behavioral patterns in terms of adaptive resource allocation, as it may have helped them to stabilize their body's equilibrium in a situation in which they may be operating closer to their stability boundaries than young adults.

\section{Assistive Technologies in Old Age}

The sensorimotor-cognitive couplings project also investigates assistive technology in adulthood and old age. Figure 10 summarizes the psychological principles of successful aging technologies (Lindenberger, Lövdén, Schellenbach, Li, \& Krüger, 2008). In order to be effective, technological devices need to release more cognitive resources for other tasks than are needed for their operation (net resource release). They also need to be person-specific, by taking into consideration the prerequisites of each aging individual, by using cues generated by the individual, and by relying on learning algorithms that flexibly adapt the device to the needs and behavioral regularities of the individual. When evaluating assistive technologies, it needs to be assessed whether long-term benefits (e.g., the uncovering of an individual's latent potential) outweigh long-term risks (e.g., the depletion of resources through the chronic use of technological assistance).

The larger context of this applied work is to specify and implement psychological criteria for the design of effective assistive technology, with a special consideration of age-graded changes in cognitive and sensorimotor abilities. By continuously adjusting the balance between "environmental support" and "self-initiated processing" (Craik, 1983) in person-specific and

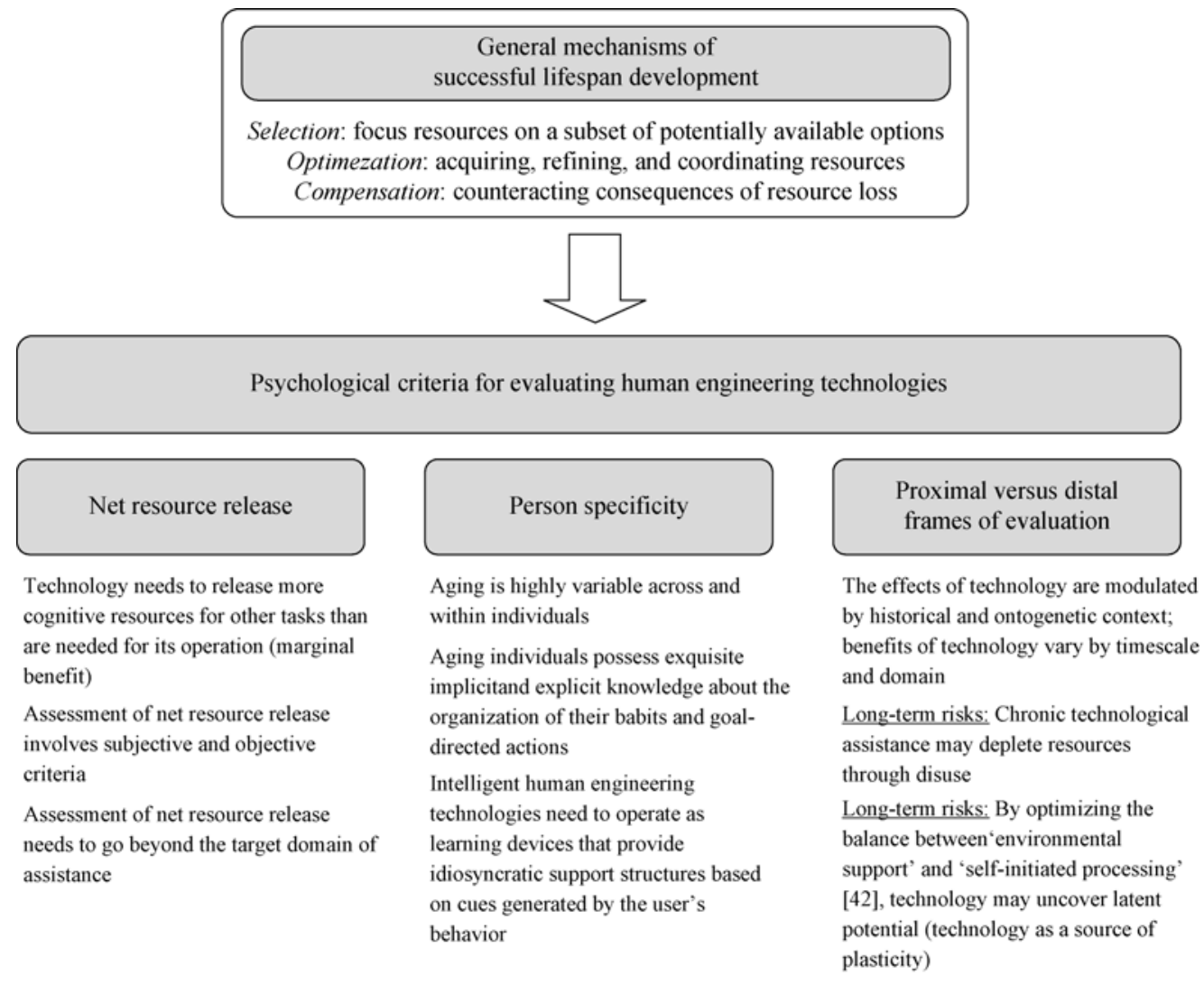

Figure 10. Psychological principles of successful aging technologies. 
aging-sensitive ways, intelligent assistive technology can promote successful aging by enhancing cognitive resource allocation. Furthermore, intelligent assistive technology may foster the generation of formerly latent cognitive resources by activating developmental reserves. Thus, assistive technology may play an important role in plasticity and serve as model case for studying behavior-brain-environment interactions.

\section{Research Context and Cooperation}

In this article, we have sketched the conceptual agenda of the Center for Lifespan Psychology, and provided a selective overview of its on-going research activities. In conclusion, we would like to note that much of the work at the Center is carried out in cooperation with researchers from the other research units of the institute, from other institutions in Berlin and Potsdam, and from other institutions around the world. Of the numerous collaborations in graduate training and research that include or have been initiated by other institutions in Berlin and Potsdam, we would like to mention: (a) the International Max Planck Research School "The Life Course: Evolutionary and Ontogenetic Dynamics" (LIFE), which includes the Max Planck Institute for Human Development, the Free University, the Humboldt University, the University of Michigan, and the University of Virginia; (b) the Berlin School of Mind and Brain, which is housed at the Humboldt University; (c) the Berlin NeuroImaging Center, a joint initiative by the Charité Universitätsmedizin Berlin, the Humboldt University, the Free University, the Physikalisch Technische Bundesanstalt, and the Max Planck Institute for Human Development; (d) the Cooperative research unit on Conflicts as Signals in Cognitive Systems, which is funded by the Deutsche Forschungsgemeinschaft and co-ordinated at the Humboldt University; (e) the Maxnet Cognition, a research network on cognition supported by the Max Planck Society.

Finally, we would like to express our special gratitude to the neighboring universities in Berlin and Potsdam, in general, and the psychology departments of the Free University, the Humboldt University, and the University of Potsdam, in particular. The three psychology departments are the institutions at which most of the Center's student research assistants are enrolled, from which most of the Center's predoctoral students receive their doctoral degree, and at which most of the Center's scientific staff are invited to teach their seminars and lectures. If the research projects of the Center have been productive and the careers of its students, predoctoral fellows, and research scientists successful, then the neighboring universities deserve much of the credit.

\section{References}

Anokhin, A. P., Müller, V., Lindenberger, U., Heath, A. C., \& Myers, E. (2006). Genetic influences on dynamic complexity of brain oscillations. Neuroscience Letters, 397, 93-98.

Bäckman, L., Nyberg, L., Lindenberger, U., Li, S.-C., \& Farde, L. (2006). The correlative triad among aging, dopamine, and cognition: Current status and future projects. Neuroscience and Biobehavioral Reviews, 30, 791-807.

Baltes, P. B. (in press). Entwurf einer Lebensspannen-Psychologie der Sehnsucht: Utopie eines vollkommenen und perfekten Lebens. Psychologische Rundschau.

Baltes, P. B. (1987). Theoretical propositions of life-span developmental psychology: On the dynamics between growth and decline. Developmental Psychology, 23, 611-626.

Baltes, P. B., \& Kliegl, R. (1992). Further testing of limits of cognitive plasticity: Negative age differences in a mnemonic skill are robust. Developmental Psychology, 28, 121-125.

Baltes, P. B., Lindenberger, U., \& Staudinger, U. M. (1998). Life-span theory in developmental psychology. In W. Damon (Series Ed.) \& R. M. Lerner (Vol. Ed.), Handbook of child psychology: Vol. 1. Theoretical models of human development (5th ed., pp. 1029-1143). New York: Wiley.

Baltes, P. B., Lindenberger, U., \& Staudinger, U. M. (2006). Life span theory in developmental psychology. In W. Damon \& R. M. Lerner (Eds.), Handbook of child psychology: Vol. 1. Theoretical models of human development (6th ed., pp. 569-664). New York: Wiley.

Brehmer, Y., Li, S.-C., Müller, V., Oertzen, T. von, \& Lindenberger, U. (2007). Memory plasticity across the life span: Uncovering children's latent potential. Developmental Psychology, 43, 465-478.

Brehmer, Y., Li, S.-C., Straube, B., Stoll, G., Oertzen, T. von, Müller V., \& Lindenberger, U. (2008). Maintenance of skilled episodic memory performance over 11 months: Stability in adults and improvement in children. Psychology and Aging, 23, 227-238.

Carstensen, L. L. (1993). Motivation for social contact across the life-span: A theory of socioemotional selectivity. In J. E. Jacobs (Ed.), Nebraska symposium on motivation (Vol. 40, pp. 209-254). Lincoln, NE: University of Nebraska Press. 
Cattell, R. B. (1952). Factor analysis: An introduction and manual for the psychologist and social scientist. New York: Harper.

Craik, F. I. M. (1983). On the transfer of information from temporary to permanent memory. Philosophical Transactions of the Royal Society of London, B302, 341-359.

Craik, F. I. M. (2006). Brain-behavior relations across the lifespan: A commentary. Neuroscience and Biobehavioral Reviews, 30, 885-892.

Craik, F. I. M., \& Bialystok, E. (Eds.) (2006). Lifespan cognition: Mechanisms of change (pp. 297-314). Oxford, UK: Oxford University Press.

Dehaene, S. \& Cohen, L. (2007). Cultural recycling of cortical maps. Neuron, 56, 384-398.

Drewing, K., Aschersleben, G., \& Li, S.-C. (2006). Sensorimotor synchronization across the lifespan. International Journal of Behavioral Development, 30, 280-287.

Dunlosky, J., Hertzog, C., \& Powell-Moman, A. (2005). The contribution of mediator-based deficiencies to age differences in associative learning. Developmental Psychology, 41, 389-400.

Ebner, N. C., Freund, A. M., \& Baltes, P. B. (2006). Developmental changes in personal goal orientation from young to late adulthood: From striving for gains to maintenance and prevention of losses. Psychology and Aging, 21, 664-678.

Gerstorf, D., Lövdén, M., Röcke, C., Smith, J., \& Lindenberger, U. (in press). Well-being affects changes in perceptual speed in advanced old age: Longitudinal evidence for a dynamic link. Developmental Psychology.

Ghisletta, P., \& Lindenberger, U. (2003). Age-based structural dynamics between perceptual speed and knowledge in the Berlin Aging Study: Direct evidence for ability dedifferentiation in old age. Psychology and Aging, 18, 696-713.

Ghisletta, P., McArdle, J. J., \& Lindenberger, U. (2006). Longitudinal cognition-survival relations in old and very old age. European Psychologist, 11, 204-223.

Goldberg, T. E., \& Weinberger, D. R. (2004). Genes and the parsing of cognitive processes. Trends in Cognitive Sciences, 8, 325-335.

Hertzog, C., Kramer, A. F., Wilson, R. S., \& Lindenberger, U. (in press). Enrichment effects on adult cognitive development: Can the functional capacity of older adults be preserved and enhanced? Psychological Science in the Public Interest, 19, 1-65.

Hertzog, C., Lindenberger, U., Ghisletta, P., \& Oertzen, T. von (2006). On the power of multivariate latent growth curve models to detect individual differences in change. Psychological Methods, 11, 244-252.

Huxhold, O. (2007). Processing fluctuations in postural control: Relations to adult age and fluctuations in cognition. Doctoral thesis, Free University of Berlin and Max Planck Institute for Human Development, Berlin, Germany.

Huxhold, O., Li, S.-C., Schmiedek, F., \& Lindenberger, U. (2006). Dual-tasking postural control: Aging and the effects of cognitive demand in conjunction with focus of attention. Brain Research Bulletin, 69, 294-305.

Kempermann, G. (2005). Adult neurogenesis: Stem cells and neuronal development in the adult brain. Oxford, UK: Oxford University Press

Lautrey, J. (2003). A pluralistic approach to cognitive differentiation and development. In R. J. Sternberg \& J. Lautrey (Eds.), Models of intelligence: International perspectives (pp. 117-131). Washington, DC: American Psychological Association.

Li, K. Z. H., Lindenberger, U., Freund, A. M., \& Baltes, P. B. (2001). Walking while memorizing: Age-related differences in compensatory behavior. Psychological Science, 12, 230-237.
Li, S.-C. (2002). Connecting the many levels and facets of cognitive aging. Current Directions in Psychological Science, 11, 38-43.

Li, S.-C. (2003). Biocultural orchestration of developmental plasticity across levels: The interplay of biology and culture in shaping the mind and behavior across the life span. Psychological Bulletin, 129, 171-194.

Li, S.-C., Chicherio, C., Nyberg, L., von Oertzen, T., Nagel, I.E., Papenberg, G., Sander, T., Heekeren, H., Lindenberger, U., \& Bäckman, L. (in press). Ebbinghaus revisited: Influences of the BDNF Val66Met polymorphism on backward serial recall are modulated by human aging. Journal of Cognitive Neuroscience.

Li, S.-C., Huxhold, O., \& Schmiedek, F. (2004). Aging and processing robustness: Evidence from cognitive and sensorimotor functioning. Gerontology, 50, 28-34.

Li, S.-C., \& Lindenberger, U. (1999). Cross-level unification: A computational exploration of the link between deterioration of neurotransmitter systems and dedifferentiation of cognitive abilities in old age. In L.-G. Nilsson \& H. J. Markowitsch (Eds.), Cognitive neuroscience of memory (pp. 103-146). Seattle, WA: Hogrefe \& Huber.

Li, S.-C., \& Lindenberger, U. (2002). Co-constructed functionality instead of functional normality: Dynamic biocultural co-construction of brain-behaviour mappings [Invited commentary]. Behavioral and Brain Sciences, 25, 761-762.

Li, S.-C., Lindenberger, U., Hommel, B., Aschersleben, G., Prinz, W., \& Baltes, P. B. (2004). Transformations in the couplings among intellectual abilities and constituent cognitive processes across the life span. Psychological Science, 15, 155-163.

Li, S.-C., Lindenberger, U., Nyberg, L., Heekeren, H. R., \& Bäckman, L. (2009). Dopaminergic modulation of cognition in human aging. In W. Jagust and M. D'Esposito (Eds.), Imaging the Aging Brain (pp.71-92). New York: Oxford University Press.

Li, S.-C., Lindenberger, U., \& Sikström, S. (2001). Aging cognition: From neuromodulation to representation. Trends in Cognitive Sciences, 5, 479-486.

Li, S.-C., Oertzen, T. von, \& Lindenberger, U. (2006). A neurocomputational model of stochastic resonance and aging. Neurocomputing, 69, 1553-1560.

Li, S.-C., Schmiedek, F., O. Huxhold, Röcke, C., Smith, J., \& Lindenberger, U. (2008). Working memory plasticity in old age: practice gain, transfer, and maintenance. Psychology and Aging, 23, 731-742.

Li, S.-C., \& Sikström, S. (2002). Integrative neurocomputational perspectives on cognitive aging, neuromodulation, and representation. Neuroscience and Biobehavioral Reviews, 26, 795-808.

Lindenberger, U. (2001). Lifespan theories of cognitive development. In N. J. Smelser \& P. B. Baltes (Eds.), International encyclopedia of the social and behavioral sciences (Vol. 13, pp. 8848-8854). Amsterdam: Elsevier Science.

Lindenberger, U., Li, S.-C., \& Bäckman, L. (Eds.) (2006). Methodological and conceptual advances in the study of brain-behavior dynamics: A multivariate lifespan perspective [Special issue]. Neuroscience and Biobehavioral Reviews, 30(6).

Lindenberger, U., \& Lövdén, M. (2006). Co-constructing human engineering technologies in old age: Lifespan psychology as a conceptual foundation. In P. B. Baltes, P. Reuter-Lorenz, \& F. Rösler (Eds.), Lifespan development and the brain: The perspective of biocultural co-constructivism (pp. 350-375). New York: Cambridge University Press.

Lindenberger, U., Lövdén, M., Schellenbach, M., Li, S.-C., \& Krüger, A. (2008). Psychological principles of successful aging technologies: A mini-review. Gerontology, 54, 59-68. 
Lindenberger, U., Marsiske, M., \& Baltes, P. B. (2000). Memorizing while walking: Increase in dual-task costs from young adulthood to old age. Psychology and Aging, 15, 417-436.

Lindenberger, U., Nagel, I. E., Chicherio, C., Li, S.-C., Heekeren, H. R., Bäckman, L. (2008). Age-related decline in brain resources modulates genetic effects on cognitive functioning. Frontiers in Neuroscience, 2, 234-244.

Lindenberger, U. \& Oertzen, T. V. (2006). Variability in cognitive aging: From taxonomy to theory. In F. I. M Craik \& E. Bialystok (Eds.), Lifespan cognition: Mechanisms of change (pp. 297-314). Oxford, UK: Oxford University Press.

Lövdén, M., Ghisletta, P., \& Lindenberger, U. (2005). Social participation attentuates cognitive decline in perceptual speed in old and very old age. Psychology and Aging, 20, 423-434.

Lövdén, M., Li, S.-C., Shing, Y. L., \& Lindenberger, U. (2006). Within-person trial-to-trial variability precedes and predicts cognitive decline in old and very old age: Longitudinal data from the Berlin Aging Study. Manuscript submitted for publication, Max Planck Institute for Human Development, Berlin.

Lövdén, M., \& Lindenberger, U. (2005). Development of intellectual abilities in old age: From age gradients to individuals. In O. Wilhelm \& R. W. Engle (Eds.), Handbook of understanding and measuring intelligence (pp. 203-221). Thousand Oaks, CA: Sage.

Lövdén, M., Schaefer, S., Pohlmeyer, A. E., \& Lindenberger, U. (2008). Walking variability and working-memory load in aging: A dual-process account relating cognitive control to motor control performance. Journal of Gerontology: Psychological Sciences, 63B, P121-P128.

Lövdén, M., Schellenbach, M., Grossman-Hutter, B., Krüger, A., \& Lindenberger, U. (2005). Environmental topography and postural control demands shape aging-associated decrements in spatial navigation performance. Psychology and Aging, 20, 683-694.

McArdle, J. J., \& Hamagami, F. (2001). Latent difference score structural models for linear dynamic analyses with incomplete longitudinal data. In L. M. Collins \& A. G. Sayer (Eds.), New methods for the analysis of change (pp. 137-176). Washington, DC: American Psychological Association.

Molenaar, P. C. M. (2008). On the implications of .the classical ergodic theorems: Analysis of developmental processes has to focus on intra-individual variation. Developmental Psychobiology, 50, 60-69.

Nagel, I. E., Chicherio, C., Li, S.-C., von Oertzen, T., Sander, T., Villringer, A., Heekeren, H. R., Bäckman, L., \& Lindenberger, U. (2008). Human aging magnifies genetic effects on executive functioning and working memory. Frontiers in Human Neuroscience, 2, 1-8.

Naveh-Benjamin, M. (2000). Adult age differences in memory performance: Tests of an associative deficit hypothesis. Journal of Experimental Psychology: Learning, Memory, and Cognition, 26, 1170-1187.

Nesselroade, J. R. (1991). The warp and the woof of the developmental fabric. In R. M. Downs, L. S. Liben, \& D. S. Palermo (Eds.), Visions of aesthetics, the environment and development: The legacy of Joachim Wohlwill (pp. 213-240). Hillsdale, NJ: Erlbaum.

Oertzen, T. von (in press). Power equivalence in structural equation modeling. British Journal of Mathematical \& Statistical Psychology.

Raz, N., Lindenberger, U., Rodrigue, K. M., Kennedy, K. M., Head, D., Williamson, A., Dahle, C., Gerstorf, D., \& Acker, J. D. (2005). Regional brain changes in aging healthy adults: General trends, individual differences, and modifiers. Cerebral Cortex, 15, 1676-1689

Riediger, M., \& Freund, A. M. (2006). Focusing and restricting: Two aspects of motivational selectivity in adulthood. Psychology and Aging, 21, 173-185.

Riediger, M., Li, S.-C., \& Lindenberger, U. (2006). Selection, optimization, and compensation as developmental mechanisms of adaptive resource allocation: Review and preview. In J. E. Birren \& K. W. Schaie (Eds.), Handbook of the psychology of aging (6th ed., Vol. 2., pp. 289-313). Amsterdam: Elsevier.

Röcke, C.. Li, S.-C., \& Smith, J. (in press). Intraindividual variability in positive and negative affect over 45 days: Do older adults fluctuate less than younger adults? Psychology and Aging. .

Schaefer, S., Huxhold, O., Lindenberger, S. (2006). Healthy mind in healthy body? A review of sensorimotor cognitive interdependencies in old age. European Review of Aging and Physical Activity, 3, 45-54.

Schaefer, S., Krampe, R. T., Lindenberger, U., \& Baltes, P. B. (2008). Age differences between children and young adults in the dynamics of dual-task prioritization: Body (balance) versus mind (memory). Developmental Psychology, 44, 747-757.

Schaefer, S., Lövdén, M., Wieckhorst, B., \& Lindenberger, U. (in press). Cognitive performance is improved while walking: Differences in cognitive-sensorimotor couplings between children and young adults. European Journal of Developmental Psychology.

Scheibe, S., Freund, A. M., \& Baltes, P. B. (in press). Toward a developmental psychology of Sehnsucht (life-longings): The optimal (utopian) life. Developmental Psychology.

Scheibe, S., Kunzmann, U., \& Baltes, P. B. (in press). Wisdom, life longings, and optimal development. In J. A. Blackburn \& C. N. Dulmus (Eds.), Handbook of gerontology: Evidence-based approaches to theory, practice, and policy. Hoboken, NJ: Wiley.

Schmiedek, F., Li, S.-C., \& Lindenberger, U. (2009). Interference and facilitation in spatial working memory: Age-associated differences in lure effects in the N-Back paradigm. Psychology and Aging, 24, 203-210.

Schmiedek, F., Hildebrandt, A., Lövdén, M., Wilhelm, O., \& Lindenberger, U. (2009). Complex span versus updating tasks of working memory: The gap is not that deep. Journal of Experimental Psychology: Learning, Memory, and Cognition, 35 , 1089-1096.

Shing, Y. L., Werkle-Bergner, M., Li, S.-C., \& Lindenberger, U. (2008). Associative and strategic components of episodic memory: A lifespan dissociation. Journal of Experimental Psychology: General, 137, 495-513.

Shing, Y. L., Werkle-Bergner, M., Brehmer, Y., Müller, V., Li, S.-C., \& Lindenberger, U. (in press). Episodic memory across the lifespan: The contributions of associative and strategic components. Neuroscience \& Biobehavioral Reviews.

Siegler, R. S. (1994). Cognitive variability: A key to understanding cognitive development. Current Directions in Psychological Science, 3, 1-5.

Simons, J. S., \& Spiers, H. J. (2003). Prefrontal and medial temporal lobe interactions in long-term memory. Nature Reviews Neuroscience, 4, 637-648.

Singer, T., Lindenberger, U., \& Baltes, P. B. (2003). Plasticity of memory for new learning in very old age: A story of major loss? Psychology and Aging, 18, 306-317.

Sliwinski, M., Lipton, R. B., Buschke, H., \& Stewart, W. (1996). The effects of preclinical dementia on estimates of normal cognitive functioning in aging. Journals of Gerontology: Psychological Sciences and Social Sciences, 50B, P162-P170.

Striano, T., Kopp, F., Grossmann, T., \& Reid, V. M. (2006). Eye contact influences neural processing of emotional expressions in 4-month-old 
infants. Social Cognitive and Affective Neuroscience, 1, 87-95.

Verrel, J., Lövdén, M., Schellenbach, M., Schaefer, S., \& Lindenberger, U. (2009). Interacting effects of cognitive load and adult age on the regularity of whole-body motion during treadmill walking. Psychology and Aging, 24, 75-81.

Werkle-Bergner, M., Müller, V., Li, S.-C., Lindenberger, U. (2006).
Cortical EEG correlates of successful memory encoding: Implications for lifespan comparisons. Neuroscience and Biobehavioral Reviews, 30, 893-854.

Zimmer, H. D., Mecklinger, A., \& Lindenberger, U. (Eds.) (2006). Handbook of binding and memory: Perspectives from cognitive neuroscience. Oxford: Oxford University Press.

\title{
马普人类发展研究所毕生发展心理研究中心：研究主题和研究活动展示
}

\author{
Shu-Chen Li, Martin Lövdén, Sabine Schaefer, Florian Schmiedek, Yee Lee Shing, \\ Markus Werkle-Bergner, and Ulman Lindenberger \\ (Center for Lifespan Psychology, Max Planck Institute for Human Development, Berlin, Germany)
}

\begin{abstract}
摘 要 Paul B. Baltes 于 1981 年在马普人类发展研究所成立的毕生发展心理研究中心已经使毕生发 展心理学成为了发展心理学中的一个重要的概念分支。2004 年以来, 中心已经将研究项目扩展到了 发展行为神经科学。中心主要在三个主题上开展研究工作: (1) 研究作为成熟、学习和衰老的交互作 用的结果，毕生的不同发展阶段中人类行为变化的规律: (2) 发展能够整合来自于自身机能、时间序 列、以及行为和神经层面分析等领域实证证据的理论和方法体系。(3) 通过探索不同年龄可塑性上的 差异寻找发展的机制。中心继续重点关注成人晚期和老年期, 这为理论和实践上的创新提供了独特的 机遇。同时, 中心加强了对包括婴儿期和儿童早期在内的个体发展早期阶段的研究。本文报告了来自 四项从行为和神经层面分析感觉和认知发展的研究的最新发现。
\end{abstract}

关键词 马普人类发展研究所毕生发展心理研究中心; 研究主题; 研究项目; 成人晚期和老年期 分类号 B844 